\title{
Measurement of BH3-only protein tolerance
}

\author{
Haiming Dai ${ }^{*}, 1,2,3,4$, Husheng Ding ${ }^{3,4}$, Kevin L Peterson ${ }^{3}$, X Wei Meng ${ }^{3,4}$, Paula A Schneider ${ }^{3}$, Katherine LB Knorr ${ }^{4}$ and \\ Scott H Kaufmann ${ }^{, 3,4}$
}

The BCL2 family of proteins regulates cellular life and death decisions. Among BCL2 family members, BH3-only proteins have critical roles by neutralizing antiapoptotic family members, as well as directly activating BAX and BAK. Despite widespread occurrence of BH3-only protein upregulation in response to various stresses, this process is rarely quantified. Moreover, it is unclear whether all BH3-only proteins are equipotent at inducing cell death. Here we show that BH3-only proteins increase as much as 15- to 20-fold after various treatments and define a parameter, termed BH3-only tolerance, which measures how many copies of a particular BH3-only protein can be expressed before the majority of cells in a population undergo apoptosis. We not only assess the relative contributions of anti- and proapoptotic BCL2 family members to BH3-only tolerance, but also illustrate how the study of this parameter can be used to understand cellular sensitivity to anticancer drugs and new combinations. These observations provide a new quantitative framework for assessing apoptotic susceptibility under various conditions.

Cell Death and Differentiation (2018) 25, 282-293; doi:10.1038/cdd.2017.156; published online 20 October 2017

The intrinsic apoptotic pathway has an important role in the response to various stresses. In particular, this pathway contributes to cellular demise during embryogenesis ${ }^{1,2}$ and after DNA damage, loss of cytokine- or adhesion-induced signaling, or exposure to various chemotherapeutic agents. ${ }^{3-6}$ Conversely, inhibition of the intrinsic pathway through elevated expression of antiapoptotic BCL2 family members ${ }^{7,8}$ or loss of proapoptotic pathway components ${ }^{8-12}$ contributes to neoplastic transformation. ${ }^{13,14}$

Whether a specific cell will live or die reflects, in part, the balance between these pro- and antiapoptotic BCL2 family members. ${ }^{15,16}$ Upon activation, the proapoptotic family members BAK and BAX can breach the mitochondrial outer membrane (MOM), leading to cytochrome $c$ release, caspase 9 activation and subsequent apoptotic events. Genetic ${ }^{2,17}$ as well as biochemical experiments ${ }^{18-23}$ have indicated that the BH3-only proteins BIM, PUMA, a protease generated BID fragment (tBID), and, in some studies, NOXA can directly bind and activate BAK and/or BAX. To counteract these effects, antiapoptotic BCL2 family members such as BCL2, BCLX and MCL1 bind and neutralize activated $B A X$ and/or $\mathrm{BAK}^{2,6,16,24}$ as well as activated or overexpressed $\mathrm{BH} 3-$ only family members, ${ }^{25-30}$ thereby preserving MOM integrity.

Previous studies have shown that MOM permeabilization is often initiated by increases in $\mathrm{BH} 3-$ only protein expression. For example, p53-dependent and -independent transcriptional processes upregulate NOXA and PUMA, ${ }^{31,32}$ inhibition of mitogen activated protein kinase signaling enhances BIM stability, ${ }^{33,34}$ inhibitors of the mechanistic target of rapamycin (mTOR) induce both BIM and PUMA, ${ }^{35}$ and inhibition of the proteasome pathway upregulates NOXA through multiple mechanisms. ${ }^{36-38}$ Importantly, downregulation of the indicated $\mathrm{BH} 3$-only proteins impairs killing by each of the indicated treatments, ${ }^{32-35,37,38}$ indicating the critical role of $\mathrm{BH} 3$-only protein upregulation in the cytotoxicity of these stresses. Despite extensive qualitative observations such as these, however, quantitative information regarding the extent of $\mathrm{BH} 3$-only protein upregulation required to induce apoptosis and the ability of different cells to survive this upregulation is limited.

An assay called 'BH3 profiling' is being widely evaluated for its ability predict sensitivity to $\mathrm{BH} 3$ mimetics $^{39,40}$ or therapies that induce upregulation of $\mathrm{BH} 3$-only proteins. ${ }^{41,42}$ This assay involves treating mitochondria or permeabilized cells with isolated $\mathrm{BH} 3$ peptides and measuring cytochrome $\mathrm{c}$ release or mitochondrial depolarization. In a recent modification termed 'dynamic $\mathrm{BH} 3$ profiling,' cells are exposed to potential anticancer drugs versus diluent and assayed for BIM BH3 peptideinduced mitochondrial depolarization. ${ }^{43}$ Both of these assays involve rupture of the plasma membrane followed by introduction of isolated $\mathrm{BH} 3$ peptides and measurement of mitochondrial events, thereby limiting the information that can be gained regarding the role of endogenous $\mathrm{BH} 3-$ only proteins ${ }^{2}$ and non-mitochondrial antiapoptotic BCL2 family members ${ }^{44}$ in cellular responses to particular stresses.

Additional studies indicate that antiapoptotic BCL2 family members act as a network that buffers activation of BAX and $\mathrm{BAK}^{2,45}$ and suggest, contrary to earlier findings, ${ }^{29}$ that various antiapoptotic proteins might have somewhat equivalent roles in this network. ${ }^{46}$ Previous reports also indicate that each of the BH3-only proteins can induce apoptosis upon forced overexpression. ${ }^{4,14,25-30}$ Variation in the ability of different cells to tolerate increases in these proteins, however, has not been fully explored.

Building on earlier landmark work showing qualitatively that overexpressed $\mathrm{BH} 3-$ only proteins induce apoptosis and

${ }^{1}$ Anhui Province Key Laboratory of Medical Physics and Technology, Center of Medical Physics and Technology, Chinese Academy of Sciences, Hefei, China; ${ }^{2}$ Cancer Hospital, Hefei Institutes of Physical Science, Chinese Academy of Sciences, Hefei, China; ${ }^{3}$ Division of Oncology Research, Department of Oncology, Mayo Clinic, Rochester, MN, USA and ${ }^{4}$ Department of Molecular Pharmacology and Experimental Therapeutics, Mayo Clinic, Rochester, MN, USA

${ }^{*}$ Corresponding author: H Dai or SH Kaufmann, Division of Oncology Research, Experimental Therapeutics, Mayo Clinic, 200 First Street, SW, Rochester 55905, MN 55905, USA. Tel: +1 507284 8950; Fax: +1 507293 0107; E-mail: Dai.Haiming@ Mayo.edu or Kaufmann.scott@mayo.edu

Received 10.3.17; revised 17.8.17; accepted 23.8.17; Edited by S Kumar; published online 20.10.17 
overexpressed antiapoptotic BCL2 family members inhibit this effect, $^{25-30}$ the current study quantifies $\mathrm{BH} 3$-only protein action during anticancer drug-induced cellular demise. This study introduces a new parameter termed $\mathrm{BH} 3$-only tolerance, which is the amount of $\mathrm{BH} 3$-only protein beyond which only a small fraction of a cell population can survive. Here we show that BH3-only tolerance not only varies from cell line to cell line, but also changes more with alterations in expression of antiapoptotic BCL2 family members than with changes in endogenous $\mathrm{BH} 3$-only proteins.

\section{Results}

BH3-only protein upregulation in response to proapoptotic stimuli. Although $\mathrm{BH} 3-$ only proteins increase in response to various stimuli, it is difficult to assess the extent of this upregulation in most previous studies. Accordingly, two malignant lymphoid cell lines, Jurkat (T-cell acute lymphoblastic leukemia) and SKW6.4 (Epstein-Barr virustransformed B lymphocytes) were treated with a number of established and investigational anticancer agents. After identifying drug concentrations that induce apoptosis in the sensitive Jurkat cell line (Supplementary Figure S1), we examined changes in $\mathrm{BH} 3-0 n l y$ proteins previously shown to be critical for killing by these agents. ${ }^{34,35,37,38}$ The proteasome inhibitor bortezomib induced 3-fold increases in BIM and 8- to 16-fold increases in NOXA (Figure 1a); the Nedd8activating enzyme inhibitor pevonedistat-induced negligible to 3-fold increases in BIM and 4-fold increases in NOXA (Figure 1b); the mTOR dual inhibitor TAK-228 induced 2- to 3-fold increases in BIM and 2- to 10-fold increases in PUMA (Figure 1c); and the farnesyltransferase inhibitor tipifarnib induced 2- to 3-fold increases in BIM in the sensitive Jurkat line but no discernible increase in BIM or NOXA in the resistant SKW6.4 line (Figure 1d). Given the critical role of these BH3-only protein increases in drug-induced killing, ${ }^{34,35,37,38}$ these results suggested that cells can only tolerate a certain degree of $\mathrm{BH}$-only protein upregulation before dying.

Baseline levels of $\mathrm{BH} 3-$ only proteins. Although the preceding results showed that various treatments upregulate BH3-only proteins, they did not indicate whether these proteins are abundant or rare. Accordingly, we purified 13 BCL2 family members to homogeneity and used them as standards to quantitate endogenous levels in both Jurkat and SKW6.4 cells. As indicated in Figure 2, BID, the inactive precursor of the activator BH3-only protein tBID, was the most abundant BCL2 family member at $1.4-1.7 \times 10^{5}$ copies per cell. The antiapoptotic proteins BCL2, BCLX $\mathrm{L}_{\mathrm{L}}$ MCL1 were next most abundant. The other $\mathrm{BH} 3$-only proteins were expressed in relatively modest amounts at baseline $\left(0.8 \times 10^{3}\right.$ to $4 \times 10^{4}$ molecules per cell). Aside from BID, all of the $\mathrm{BH} 3-$ only proteins were expressed at much lower levels than antiapoptotic proteins, illustrating the potentially high buffering capacity of the antiapoptotic BCL2 family members in both of these cell lines. Moreover, BIM levels were particularly low in SKW6.4 cells (Figure 2), providing a potential explanation for resistance of SKW6.4 cells to BIM-inducing stimuli such as TAK-228 and bortezomib despite the same 'fold increase' in BIM levels (Supplementary Figures S1a and $\mathrm{c}$ ).

Determination of cellular tolerance for BH3-only proteins. In further experiments, we examined the impact of EGFPconjugated BH3-only proteins (Supplementary Figure S2) on Jurkat and SKW6.4 cell survival using annexin-V staining, a well-established marker of apoptosis. ${ }^{47,48}$ When Jurkat cells were transfected with EGFP, $75-80 \%$ of the cells were simultaneously EGFP ${ }^{+}$and annexin- $\mathrm{V}^{-}$(Figures $3 a$ and $b$ ). In contrast, when cells were transfected with EGFP-BIM $\mathrm{EL}_{\mathrm{L}}$ in the same experiments, a smaller number cells were EGFP ${ }^{+}$ (Figure 3c, upper panel, and 3d); and the fluorescence intensity was $\sim 16$-fold lower in EGFP-BIM EL $_{\text {L }}$ cells than in $\mathrm{EGFP}^{+}$(mean fluorescence intensity 96 versus 1600). When the caspase inhibitor Q-VD-OPh was added after transfection, expression of EGFP did not change (Figures $3 a$ and b), but the mean fluorescence intensity in the EGFP-BIM ${ }_{\mathrm{EL}}^{+} /$ annexin- $\mathrm{V}^{-}$population increased by 16.2 \pm 2.4 -fold (Figure 3c, top versus bottom panel, and Figure 3d). Similar effects were observed with PUMA, NOXA, BMF, BIK and HRK (Figures 3e-i and Supplementary Figures S3a-c). In contrast, EGFP-BAD was readily expressed at higher levels and with much less change in EGFP fluorescence in the absence versus presence of Q-VD-OPh (Figure $3 \mathrm{j}$ and Supplementary Figures S3d).

Conceptually, results in Figures 3c-i and Supplementary Figures S3a-c indicate that cells are able to tolerate much higher expression of certain BH3-only family members when cell death is inhibited. To quantitate this ability of cells to tolerate various $\mathrm{BH} 3-$ only proteins, we established the level of fusion protein beyond which only $2 \%$ of cells were able to survive, that is, remain Annexin- $\mathrm{V}^{-}$, in the absence of $\mathrm{Q}-\mathrm{VD}$ OPh (dashed lines, Figures 3d-j). This level, which we term the $\mathrm{BH} 3$-only tolerance, varied among the $\mathrm{BH}$-only proteins. For example, the tolerance of Jurkat cells for BIM was $\sim 110$ fluorescence units, whereas the tolerance for BIK was $\sim 240$ fluorescence units (Figures $3 d$ and $h$ ).

To convert this EGFP fluorescence to molecules per cell, each flow cytometry experiment included beads with defined numbers of FITC molecules (Supplementary Figure S4a). After fluorescence intensity versus FITC content was plotted for these beads, fluorescence of cells transfected with EGFP fusion proteins was compared with this standard curve to calculate FITC equivalents per cell. By comparing the fluorescence intensities of purified GST-EGFP (Supplementary Figure S4b) and fluorescein, we then converted from FITC equivalents to molecules of EGFP fusion protein per cell as indicated in Supplementary Figures S4C and S4d.

These experiments indicated that the tolerance of Jurkat cells for BIM, PUMA, NOXA, BMF, BIK or HRK in the absence of $\mathrm{Q}-\mathrm{VD}-\mathrm{OPh}$ ranged from 1.2 to $2.8 \times 10^{5}$ molecules per cell, with BIK and BMF being slightly better tolerated than the others (Figure 3k). In contrast, Jurkat cells were able to tolerate almost 100-fold more BAD (Figure 3k and Supplementary Figure S3d). Similar results were observed in SKW6.4 cells (Figure 3I and Supplementary Figures S3f-i). 

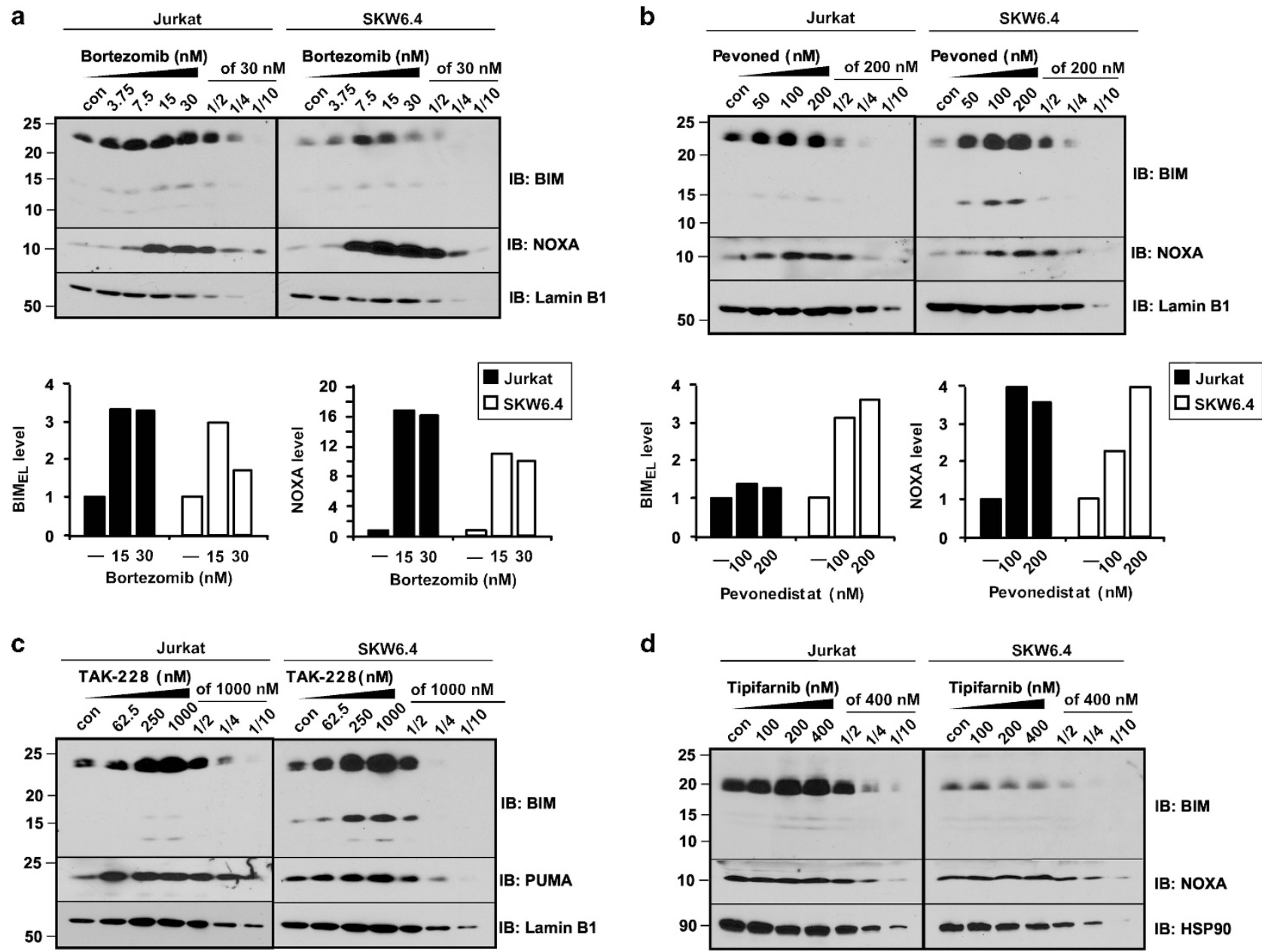

d
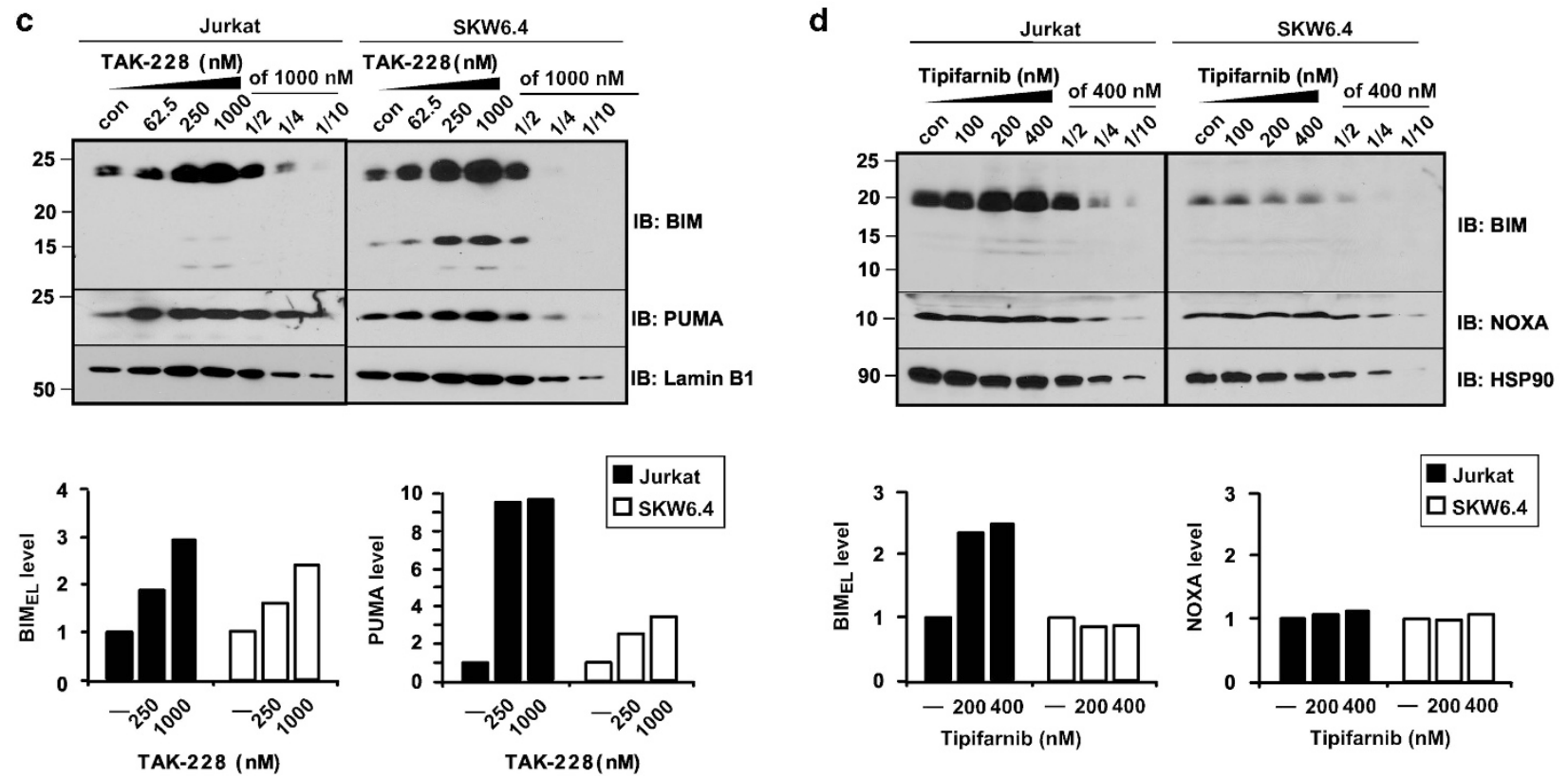

Figure 1 Anticancer drugs induce BH3-only protein upregulation. After Jurkat (left) and SKW6.4 (right) cells were treated with indicated concentrations of bortezomib (a), pevonedistat (pevoned; b), TAK-228 (c) and tipifarnib (d) for $24 \mathrm{~h}$ (a) or $48 \mathrm{~h}(\mathbf{b}-\mathbf{d})$, whole-cell lysates were separated by SDS-PAGE and probed for the indicated antigens. Serial dilutions of whole-cell lysates treated with the highest drug concentration were also loaded to calculate the fold increase of BH3-only proteins. Bottom panels, fold increases of BH3-only proteins after drug treatments. Data shown here are representative of at least three independent experiments

BH3-only tolerance varies with expression of antiapoptotic BCL2 family members. To assess whether BH3-only protein tolerance could vary under different conditions, Jurkat cells were transfected with S peptide-tagged wild-type BCL2 or MCL1, allowed to recover for $24 \mathrm{~h}$, and then transfected with EGFP/BH3-only fusion proteins (Figure 4a). As might be predicted from earlier results (e.g., 2,4,6,13,14,25-30,39), antiapoptotic BCL2 family proteins diminished apoptosis induced by all of the BH3-only proteins (Figure $4 a$, left panel). When

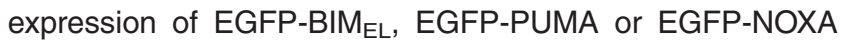

was examined, the fluorescence of cells transfected in the absence Q-VD-OPh increased upon overexpression of BCL2 or MCL1 (Figures 4b-d and Supplementary Figures S5a-c).

Importantly, effects of BCL2 and MCL1 on tolerance of $B_{E L}$, PUMA and NOXA differed (Figures 4b-e). Contrary to the recent suggestion that all antiapoptotic BCL2 family members might have similar effects, ${ }^{46}$ we observed that wild-type BCL2 and MCL1 increased the tolerance for BIM $\mathrm{EL}_{\mathrm{E}}$ about equally (Figures $4 \mathrm{~b}$ and e), whereas BCL2 preferentially increased PUMA tolerance (Figure 4c) and MCL1, which 
a

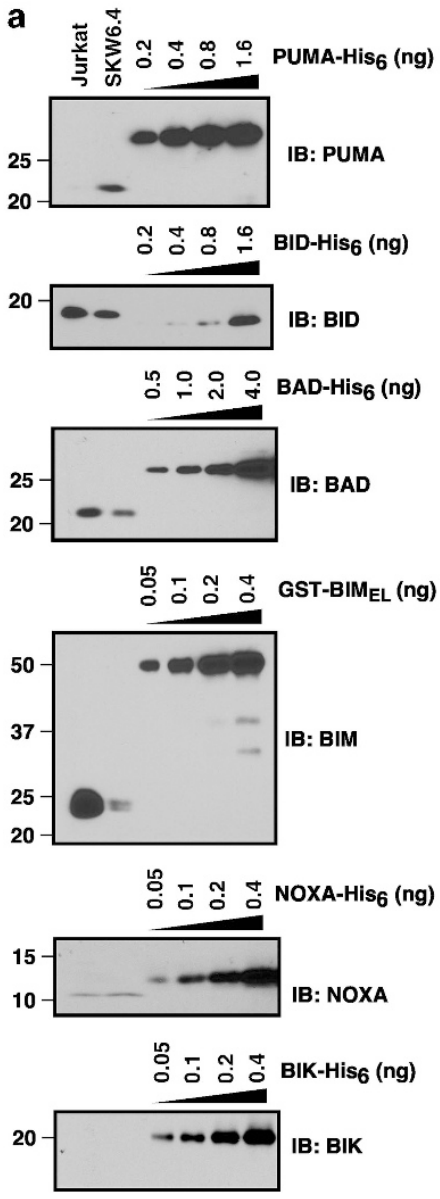

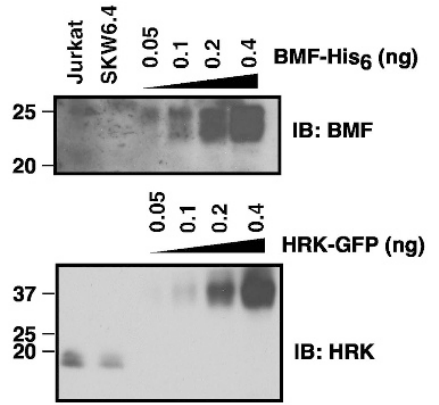

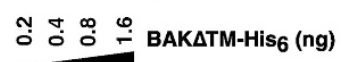

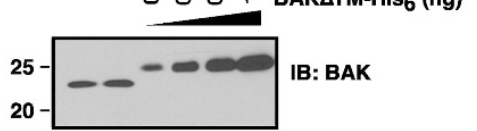

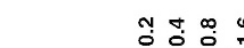
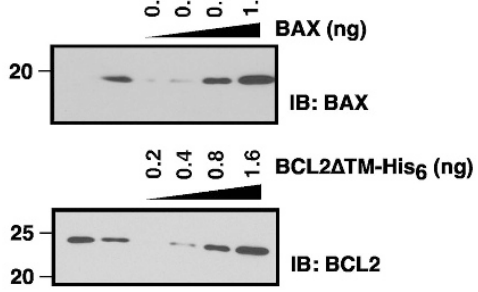

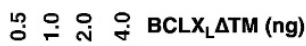
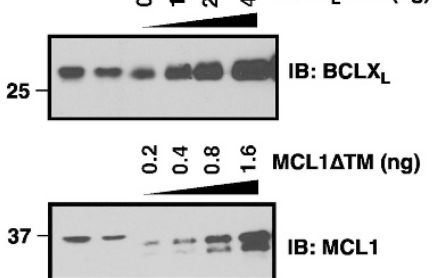

b

\begin{tabular}{ccc} 
& $\begin{array}{c}\text { Estimated Protein } \\
(\text { molecules/cell) }\end{array}$ \\
\hline & Jurkat & SKW6.4 \\
\hline PUMA & $1670 \pm 410$ & $9320 \pm 1900$ \\
BID & $171000 \pm 6400$ & $141200 \pm 6400$ \\
BAD & $38600 \pm 7700$ & $20600 \pm 4500$ \\
BIMEL & $10600 \pm 4300$ & $750 \pm 120$ \\
NOXA & $5900 \pm 2600$ & $8100 \pm 2800$ \\
BMF & $<4000$ & $<4000$ \\
HRK & $6800 \pm 600$ & $5400 \pm 600$ \\
BIK & $<4800$ & $<4800$ \\
BAK & $35400 \pm 6300$ & $28100 \pm 9700$ \\
BAX & $4800 \pm 2000$ & $65800 \pm 17100$ \\
BCL2 & $157000 \pm 54500$ & $104700 \pm 31500$ \\
BCLX & $113200 \pm 35600$ & $82300 \pm 23600$ \\
MCL1 & $57300 \pm 25000$ & $37600 \pm 11000$ \\
\hline & & \\
\hline & &
\end{tabular}

Figure 2 BCL2 family protein expression in untreated Jurkat and SKW6.4 cells. (a) Whole-cell lysates from $3 \times 10^{5}$ Jurkat and SKW6.4 cells were probed for PUMA, BID, BAD, BIM, NOXA, BIK, BMF, HRK, BAK, BAX, BCL2, BCLX ${ }_{L}$ and MCL1. Twofold dilutions of purified PUMA-His $(0.2-1.6 \mathrm{ng}), \mathrm{BID}_{6} \mathrm{His}_{6}(0.2-1.6 \mathrm{ng}), \mathrm{BAD}-\mathrm{His}_{6}(0.5-4.0 \mathrm{ng})$,

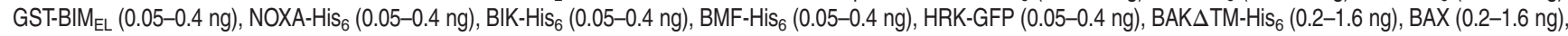
$\mathrm{BCL}_{2} \Delta \mathrm{TM}-\mathrm{His}_{6}(0.2-1.6 \mathrm{ng}), \mathrm{BCLX} \Delta \mathrm{TM}(0.5-4.0 \mathrm{ng})$ and MCL1 $\Delta \mathrm{TM}(0.2-1.6 \mathrm{ng})$ were loaded as standards for quantitation. (b) BCL2 family protein expression in non-treated Jurkat and SKW6.4 cells, mean \pm S.D. from whole-cell lysates of three independent experiments

binds Noxa more tightly, ${ }^{29,37}$ preferentially increased NOXA tolerance (Figures $4 \mathrm{~d}$ and e). Interestingly, MCL1 also protected better than BCL2 against EGFP-BAD-induced apoptosis (Figure 4a) although BCL2 has a stronger affinity for BAD. $^{29}$ This paradoxical observation might reflect the finding that partially activated BAK is extensively bound to $B C L X_{L}$ in Jurkat cells ${ }^{24}$ and, upon displacement by BAD, would be buffered better by MCL1. ${ }^{49}$

When the impact of BIM siRNA was assessed, BIM knockdown by $90 \%$ (Figure 4f, right panel) enhanced the tolerance for all of the other BH3-only proteins only minimally (Figures $4 \mathrm{f}-\mathrm{j}$ and Supplementary Figures S5e-g). In head-to-head comparisons, the change in $\mathrm{BH} 3$-only tolerance was far smaller after BIM knockdown than after overexpression of antiapoptotic BCL2 family members (Supplementary Figures S5h and i).

To further assess the impact of antiapoptotic BCL2 family members, we examined K562 and HCT116 cells, two lines with higher endogenous BCLX $\mathrm{L}_{\mathrm{L}}$ and MCL1 levels (Figure 5a). In these lines, tolerance for all of the BH3-only proteins was higher (cf. Figures $5 \mathrm{~b}$ and c versus Figure $3 \mathrm{k}$ ). This analysis accurately predicted that K562 cells would be tolerant of bortezomib-induced NOXA upregulation (Figures $5 d-f$ ). In contrast, HCT116 cells readily underwent bortezomib-induced apoptosis, reflecting the higher basal and drug-induced levels of NOXA as well as the drug-induced upregulation of BIM, a less tolerated $\mathrm{BH} 3$-only protein, specifically in this line and not in K562 cells (Figures 5d-f).

As might be expected, expression of multi-domain proapoptotic BCL2 family members also had a role in BH3-only protein tolerance. BAK gene interruption in Jurkat cells (Figure 6a), which have much more BAK than BAX (Figure 2b), markedly diminished the cytoxicity of BH3-only fusion proteins (Figure 6b). Accordingly, the tolerance for various $\mathrm{BH} 3$-only proteins increased 3 - to 15 -fold with $B A K$ knockout (cf. Figure $6 \mathrm{c}$ versus $3 \mathrm{k}$ ).

Changes in tolerance predict a novel chemotherapeutic combination. In further experiments, we examined whether changes in BH3-only tolerance could be utilized to predict therapeutic efficacy of new combinations. As indicated in 

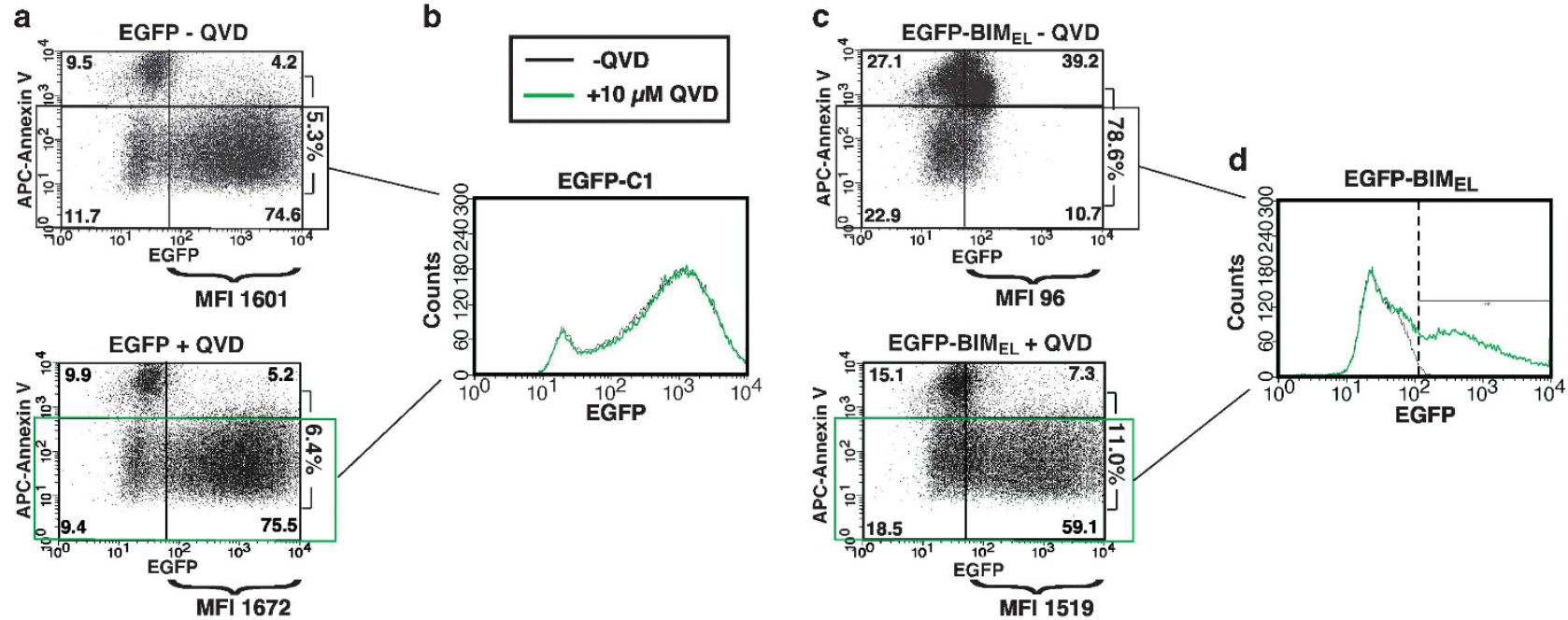

e

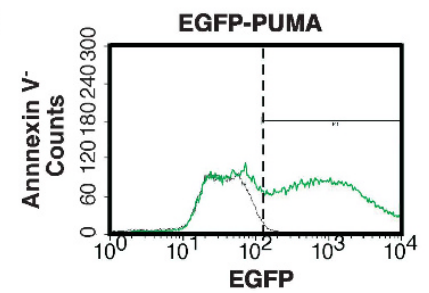

h

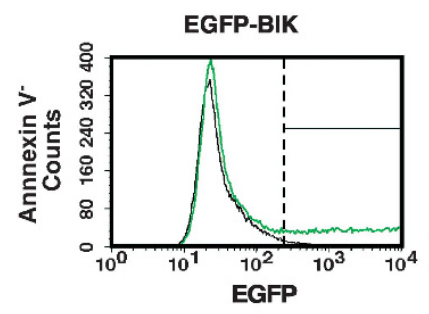

f

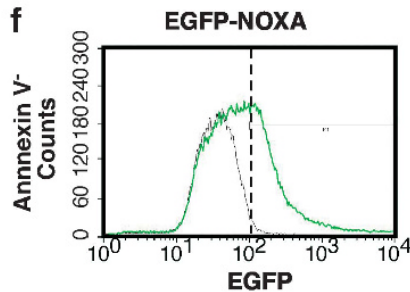

i

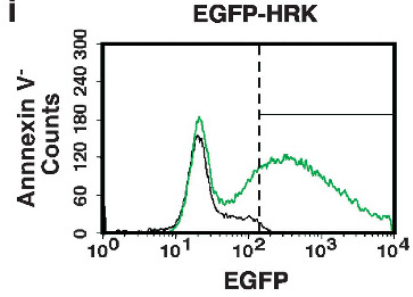

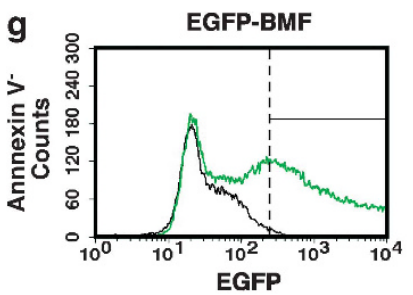

j

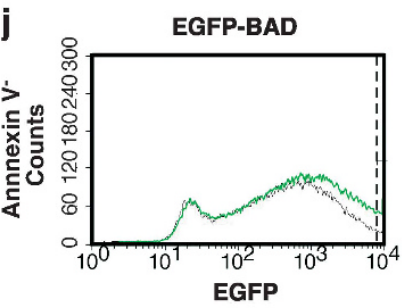

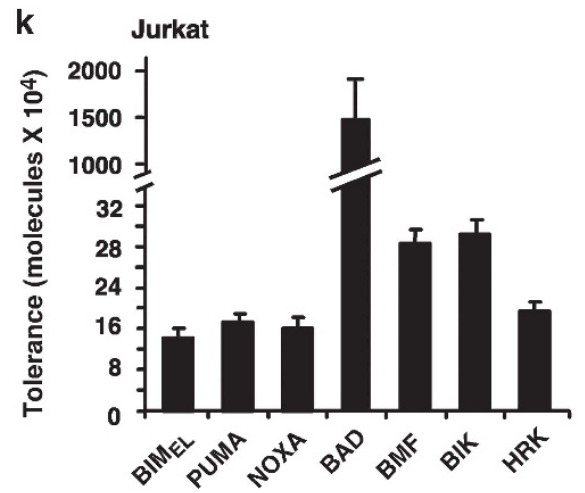

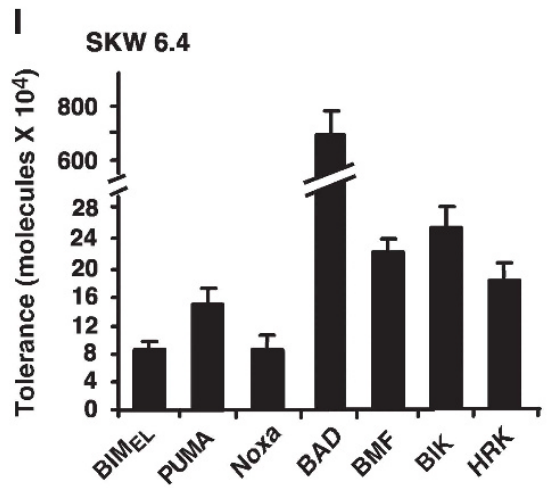

Figure 3 Calculation of BH3-only protein tolerance in Jurkat and SKW6.4 cells. (a) After Jurkat cells were transfected with EGFP-C1 and incubated for $24 \mathrm{~h}$ in the absence (top panel) or presence (bottom panel) of $10 \mu \mathrm{M} \mathrm{Q-VD-OPh,} \mathrm{cells} \mathrm{were} \mathrm{stained} \mathrm{with} \mathrm{APC-Annexin.} \mathrm{(b)} \mathrm{The} \mathrm{EGFP} \mathrm{histograms} \mathrm{of} \mathrm{the} \mathrm{non-apoptotic} \mathrm{(Annexin-V}{ }^{-}$) cells from panel a were overlaid. (c) Jurkat cells were transfected with EGFP-BIM $\mathrm{EL}_{\text {, }}$ split into two aliquots, incubated for $24 \mathrm{~h}$ in the absence (top) or presence (bottom) of Q-VD-OPh, and stained with APC-Annexin-V. Numbers at the right of dot plots represent ratio of events in upper right panel to the sum of lower right and upper right. MFI, mean fluorescence intensity of EGFP $^{+}$cells. (d-j) Overlays of EGFP fluorescence in the non-apoptotic (Annexin- $V^{-}$) population after Jurkat cells were transfected with plasmids encoding EGFP-tagged BIM $\mathrm{EL}_{\text {. }}$ (d), PUMA (e), NOXA (f), BMF (g), BIK (h), HRK (i) or BAD (j), split into two aliquots, and incubated for $24 \mathrm{~h}$ in the absence (black line) or presence of Q-VD-OPh (green line) before staining with APC-Annexin-V and analysis as illustrated in panel $\mathbf{c}$. Dashed line indicates the expression level beyond which only $2 \%$ of cells survive in the absence of Q-VD-OPh (arbitrarily defined as the tolerance for that protein). ( $(\mathbf{a}$ and I) BH3-only protein tolerances calculated for Jurkat cells (k) and SKW6.4 cells (I). Error bars: mean \pm S.D. of three independent experiments 

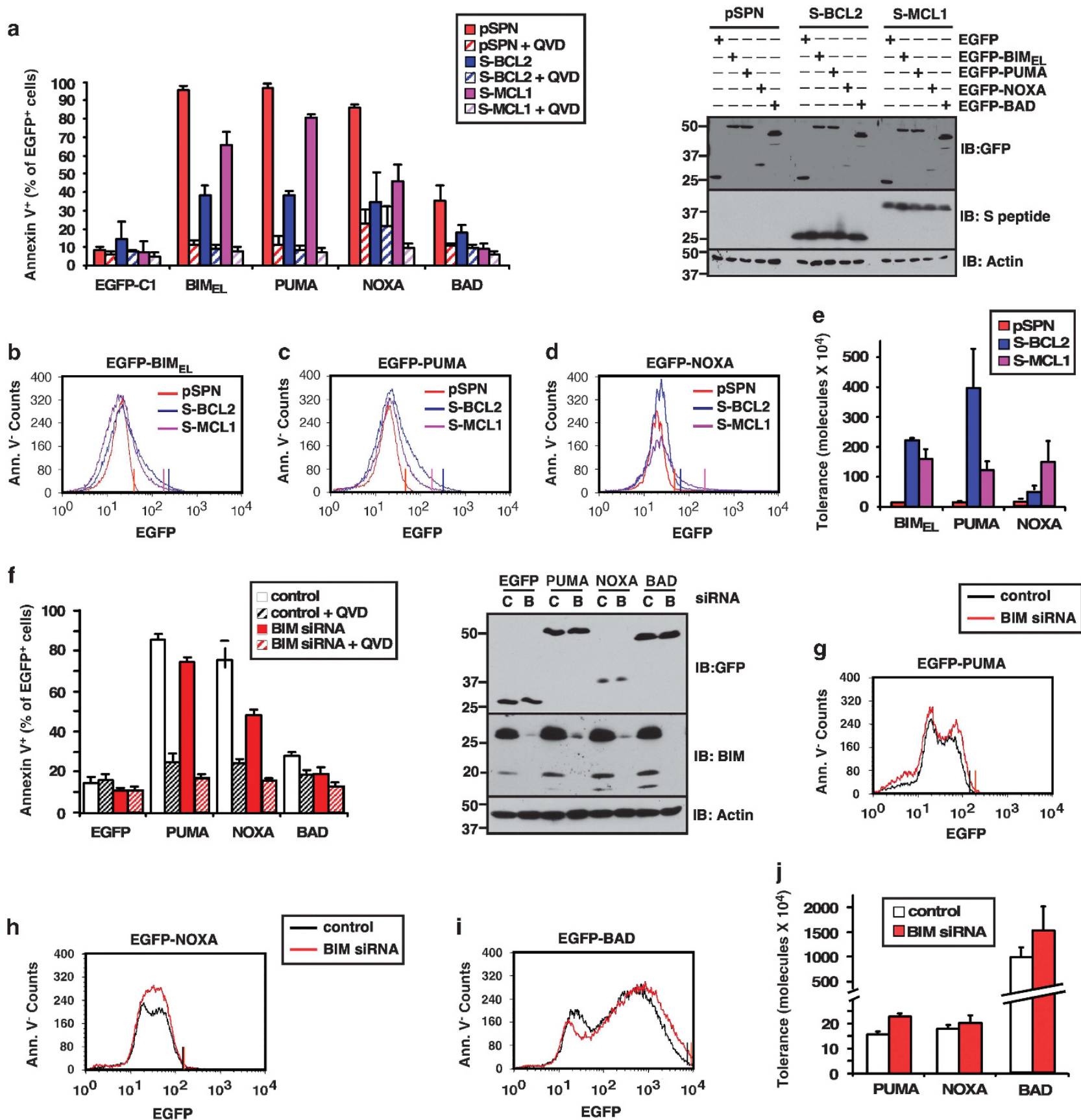

Figure 4 BH3-only tolerances change after overexpression of antiapoptotic BCL2 family members or BIM knockdown. (a) Twenty-four hours after transfection with S peptide-

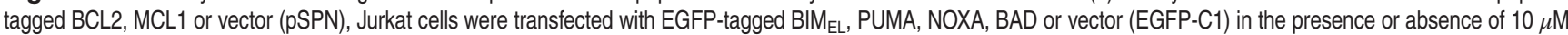
$\mathrm{Q}-\mathrm{VD}-\mathrm{OPh}$, incubated for another $24 \mathrm{~h}$, and stained with APC-Annexin-V. The percentage of EGFP ${ }^{+}$cells stained with APC-Annexin-V is indicated. Inset, western blot expression in samples from these assays. (b-d) Annexin- $V^{-}$(Ann. $V^{-}$) cells from samples transfected with control vector (red), BCL2 (blue) and MCL1 (purple) in panel A were overlaid to

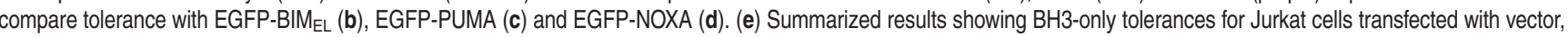
BCL2, or MCL1. (f) Twenty-four hours after Jurkat cells transfected with BIM siRNA (B) or control siRNA (C), cells were transfected with EGFP-tagged PUMA, NOXA, BAD or vector; incubated for $24 \mathrm{~h}$ in the presence or absence of $10 \mu \mathrm{M}$ Q-VD-OPh, and stained with Annexin-V APC. The percentage of EGFP+ cells stained with APC-Annexin-V is indicated. Inset, western blot showing BIM expression. ( $\mathbf{g}$-i) Non-apoptotic cells from samples transfected with vector (black) or BIM siRNA (red line) were overlaid to compare the tolerances of cells for EGFP-PUMA (g), EGFP-NOXA (h) and EGFP-BAD (i). (j) Tolerance of Jurkat cells for various BH3-only proteins when BIM is knocked down. Error bars in $\mathbf{a}, \mathbf{e}, \mathbf{f}$ and $\mathbf{j}$ : mean \pm S.D. of three independent experiments 
Figure 5 Use of BH3-only protein tolerance to understand variations in drug sensitivity. (a) Western blots showing levels of BCL2 family proteins in K562 and HCT116 cells compared with Jurkat cells. Serial dilutions of HCT116 cell whole-cell lysates were used to calculate levels of the BCL2 family proteins shown at right. (b and $\mathbf{c}$ ) The tolerances of K562 cells (b) or HCT116 cells (c) for BH3-only proteins. (d and e) After a 24- $h$ treatment with diluent or bortzemib in the absence (d) or presence (e) of $5 \mu$ M Q-VD-OPh, cells were analyzed for DNA fragmentation (d) or subjected to SDS-PAGE (e). (f) Increase in Bim and Noxa observed at indicated bortezomib concentrations in panel e. Error bars in panel a-d: mean \pm S.D. of three independent experiments. Results in panels $\mathbf{e}$ and $\mathbf{f}$, representative of three independent experiments

Figure 7a, transfection with BIM diminished the tolerance for EGFP-NOXA. Accordingly, when Jurkat cells were treated with tipifarnib, which upregulates BIM, and pevonedistat, which upregulates NOXA (Figures $1 \mathrm{~b}$ and $\mathrm{d}$ ), ${ }^{34,38}$ low concentrations of tipifarnib synergistically enhanced pevonedistat-induced killing (Figures $7 \mathrm{~b}$ and $\mathrm{c}$ ).

\section{Discussion}

Previous landmark studies have demonstrated that exogenously expressed $\mathrm{BH} 3-$ only proteins induce apoptosis in susceptible cells and overexpressed antiapoptotic BCL2 family members inhibit this apoptosis. ${ }^{25-30}$ Building on these findings, this study not only provides the first quantitative estimate of BH3-only protein expression under basal and perturbed conditions, but also suggests that the ability of cells to tolerate $\mathrm{BH} 3$-only protein upregulation is a quantifiable cellular property that varies in measurable, informative and largely predictable ways. Results of this quantitation provide new insight into the action of anticancer drugs in different cellular contexts, the relative importance of anti- versus proapoptotic BCL2 family members in setting the apoptotic threshold, and the potential of various drugs to combine in a synergistic fashion.

In this study, we have developed methods for quantitating relative cytotoxicity of proapoptotic BCL2 family members. In particular, we have defined a parameter termed BH3-only tolerance that is the amount of $\mathrm{BH}$-only protein beyond which only $2 \%$ of the cells are alive. It is important to emphasize that the $2 \%$ survival cutoff is arbitrary and similar conclusions are obtained with other cutoffs such as 5 or $10 \%$ (data not shown).

Measurement of $\mathrm{BH} 3$-only tolerance as described above differs in several important respects from $\mathrm{BH} 3$ profiling, a procedure in which $\mathrm{BH} 3$ peptides are applied to mitochondria to assess MOM permeabilization. ${ }^{39-42}$ In particular, the present study utilizes full-length $\mathrm{BH} 3$-only proteins, which differ in the strengths of their protein-protein interactions compared with isolated $\mathrm{BH} 3$ peptides, ${ }^{49}$ and places those BH3-only proteins in the context of cellular signaling networks ${ }^{2,45}$ rather than isolated mitochondria. Thus, although $\mathrm{BH} 3$ profiling is being explored as a strategy to predict sensitivity or resistance of particular cell lines or cancers to specific treatments, ${ }^{50}$ measurement of $\mathrm{BH} 3-o n l y$ tolerance has the potential to provide insight into endogenous signaling networks within intact cells that include BCL2 family members bound to surfaces other than the MOM. ${ }^{44,51}$

Despite its potential usefulness in understanding the action of drugs that upregulate $\mathrm{BH} 3-$ only proteins, measurement of $\mathrm{BH} 3-o n l y$ tolerance also has some limitations. First, because it measures cell death at a fixed point in time, it might underestimate the number of cells ultimately killed by overexpressed $\mathrm{BH} 3-$ only proteins. A similar limitation currently applies to all cell death assays. Second, by its very nature
BH3-only tolerance is designed to understand sensitivity to agents that upregulate $\mathrm{BH}$-only proteins but likely will not predict sensitivity to $\mathrm{BH} 3$ mimetics, which work through interrupting interactions among BCL2 family members. Finally, measurement of $\mathrm{BH}$-only tolerance requires successful transfection of cells and, in contrast to $\mathrm{BH} 3$ profiling, is unlikely to be feasible as a clinical test.

Measurement of BH3-only protein tolerance provides interesting insight into the balance between pro- and antiapoptotic proteins. In particular, when expression of direct activator BH3-only proteins such as BIM or PUMA is increased, the amounts of these BH3-only proteins that can be tolerated before the majority of cells in a population undergo apoptosis approximates the difference between the basal levels of pro- and antiapoptotic BCL2 family members in that cell type (cf. Figures 2b,3k and I). In Jurkat and SKW6.4 cells, the tolerance for BIK, BMF or NOXA is similar to that of $\mathrm{BIM}_{\mathrm{EL}}$ or PUMA (Figures $3 \mathrm{k}$ and I), consistent with claims that BIK, BMF and NOXA might also be direct activators in at least some contexts. ${ }^{2,20,23,52}$ In contrast, the tolerance for BAD is much higher than the tolerance for BIM and PUMA in all cell lines examined (Figures $3 \mathrm{k}, 3 \mathrm{l}, 5 \mathrm{~b}$ and $\mathrm{c}$ ). This difference between BAD and the other BH3-only proteins was particularly evident in cells with relatively low expression of BCL2 and $B_{C L} X_{L}$ (Figures $3 k$ and I). In cells with higher BCLX $X_{L}$ levels, tolerance for all of the $\mathrm{BH}$-only proteins was greater (Figures $5 \mathrm{~b}$ and $\mathrm{c}$ versus Figures $3 \mathrm{k}$ and $3 \mathrm{I}$ ), and the distinction between BAD and some of the other BH3-only proteins, notably NOXA and BIK (Figures $5 \mathrm{~b}$ and $\mathrm{c}$ ) was less clear. Although the higher tolerance for BAD across the cell lines might represent another distinction between activator and sensitizer BH3-only proteins, it is also possible that the higher tolerance reflects phosphorylation and sequestration of $B A D$, which is a well known mechanism for inactivating this particular $\mathrm{BH} 3-$ only protein.

The approach described above also provides a new perspective for examining the action of individual anticancer drugs. For example, the present analysis indicates that $98 \%$ of Jurkat cells undergo apoptosis within $24 \mathrm{~h}$ when an average of 150000 NOXA molecules per cell are expressed (Figure 3k). Further examination of histograms leading to this conclusion (e.g., Figure 3f) indicates that expression of $\sim 75000$ NOXA molecules per cell induces apoptosis in half the population. Additional experiments indicate that $15 \mathrm{nM}$ bortezomib induces $\sim 15$-fold upregulation of NOXA (Figure 1a), which is expressed at $\sim 6000$ copies per cell at baseline (Figure $2 b$ ), leading to $\sim 90000$ NOXA molecules per Jurkat cell. These independent determinations of $\mathrm{BH} 3-$ only protein sensitivity (Figure 3) and expression (Figures 1 and 2) are consistent with our observation that $66 \pm 7 \%$ of Jurkat cells are apoptotic $24 \mathrm{~h}$ after addition of $15 \mathrm{nM}$ bortezomib (Supplementary Figure S1 and $^{\text {ref. }}{ }^{37}$ ). Moreover, the fact that analyses involving endogenous Noxa (Figures 1 and 2) and EGFP-Noxa (Figure 3) 


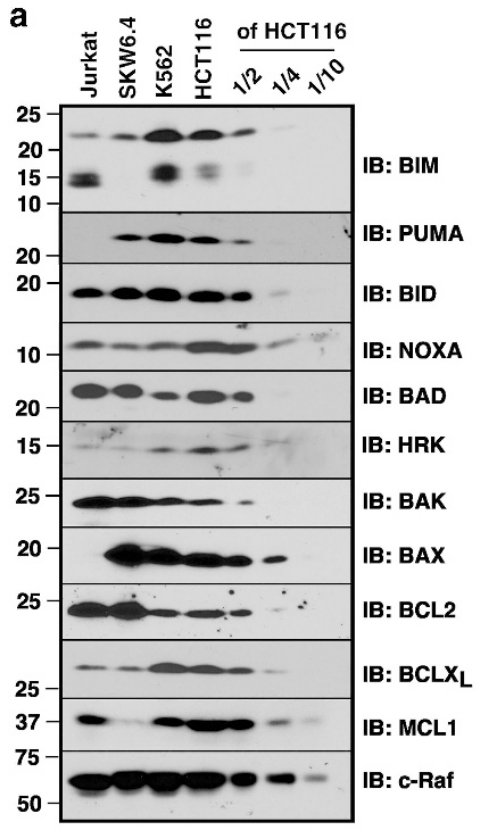

\begin{tabular}{ccc}
\multicolumn{3}{c}{$\begin{array}{c}\text { Estimated Protein Expression } \\
(\text { molecules/cell) }\end{array}$} \\
\hline & K562 & HCT-116 \\
\hline PUMA & $17000 \pm 6400$ & $12700 \pm 3400$ \\
BID & $210000 \pm 13700$ & $195600 \pm 31100$ \\
BAD & $26000 \pm 7200$ & $65900 \pm 21200$ \\
BIMEL & $34400 \pm 9300$ & $30700 \pm 6600$ \\
NOXA & $5980 \pm 310$ & $20500 \pm 5500$ \\
HRK & $19200 \pm 3600$ & $28200 \pm 5300$ \\
BAK & $20500 \pm 1900$ & $18000 \pm 1000$ \\
BAX & $33600 \pm 7400$ & $27200 \pm 4600$ \\
BCL2 & $36500 \pm 7500$ & $51100 \pm 5800$ \\
BCLX & $506400 \pm 99200$ & $410400 \pm 59000$ \\
MCL1 & $71400 \pm 1700$ & $106700 \pm 9700$ \\
\hline
\end{tabular}
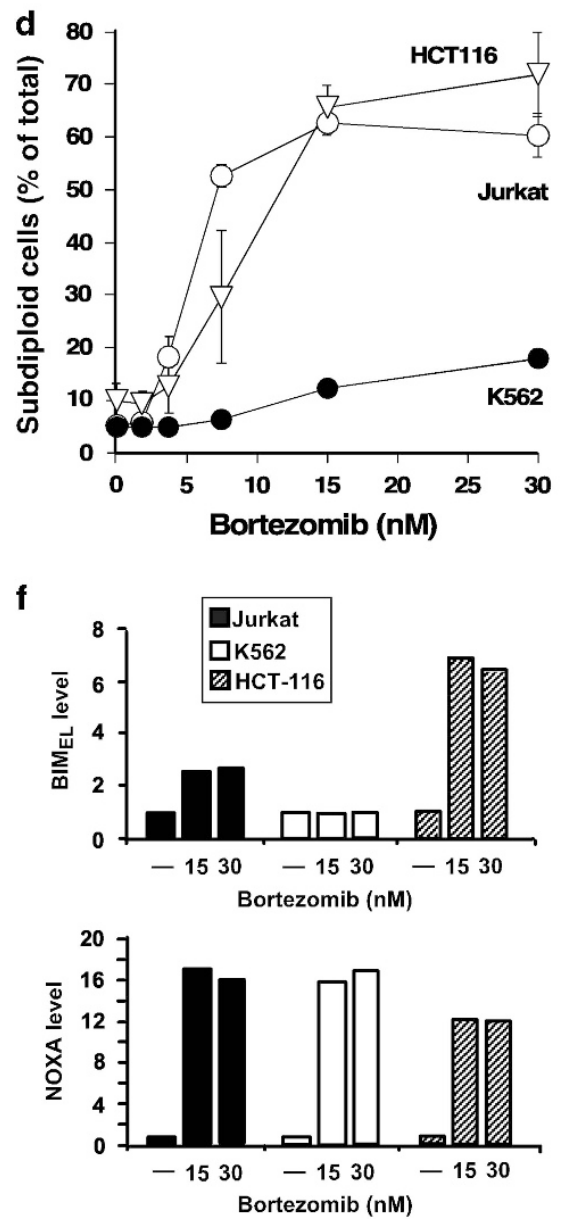
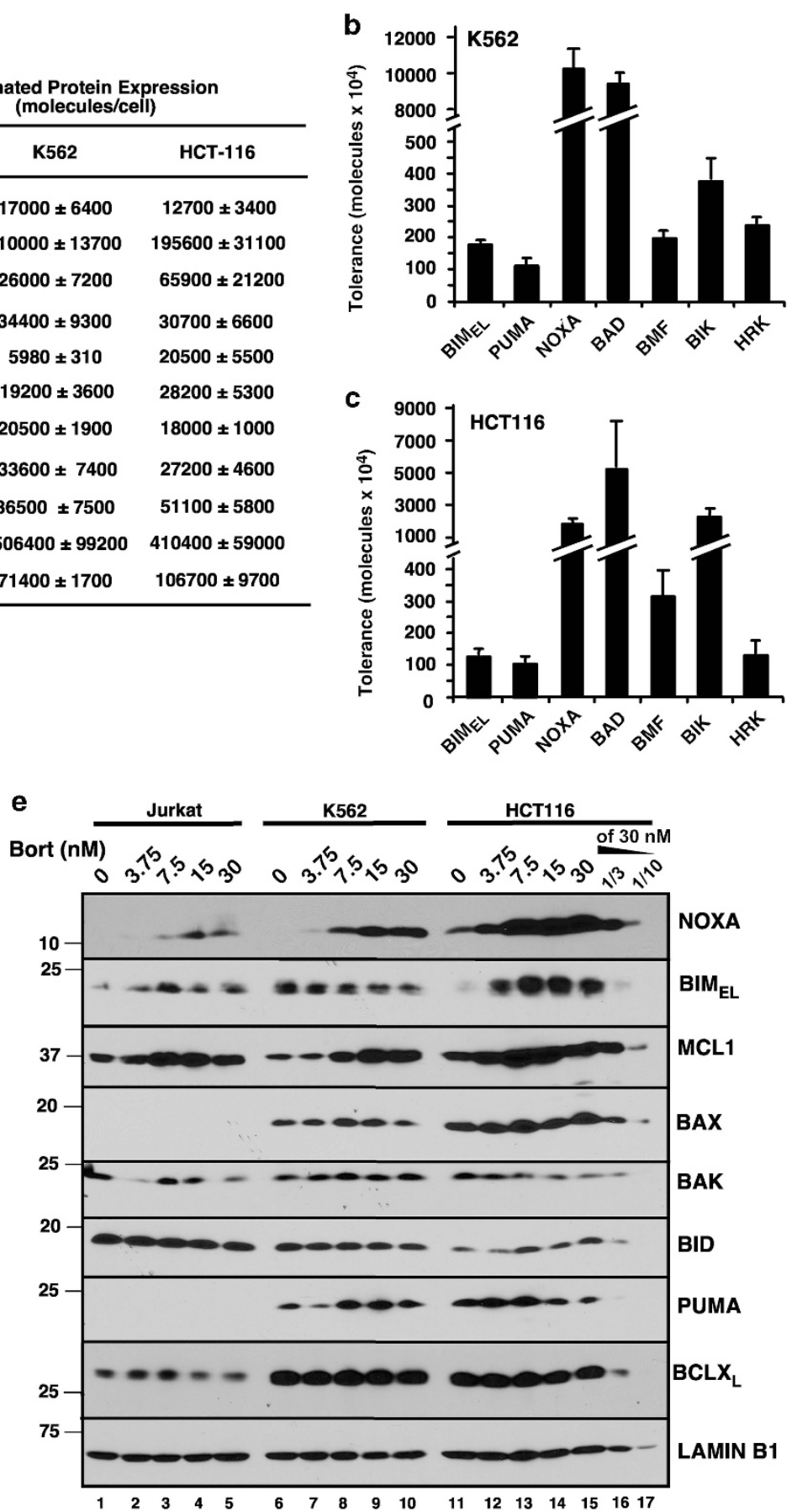

Cell Death and Differentiation 
yield comparable quantative results suggests that the actions of EGFP-Noxa and native endogenous Noxa are similar. Similarly, histograms exploring sensitivity to EGFP-BIM $\mathrm{EL}_{\mathrm{L}}(2 \%$ survival at 120000 molecules per cell, $60 \%$ survival at 25000 molecules per cell, Figure $3 d$ ) concur with results showing that $200 \mathrm{nM}$ tipifarnib, which induces upregulation of $\mathrm{BIM}_{\mathrm{EL}}$ to roughly 25000 molecules per cell (Figures 1d and 2b), kills $30-40 \%$ of cells (Supplementary Figure S1 and Ding et $a l^{34}$ ), again showing agreement between the separate methods of quantitation and suggesting that the actions of $B M_{E L}$ and EGFP-BIM $\mathrm{EL}_{\text {are similar. }}$ ar

Importantly, tolerances for BH3-only proteins vary among cell types. Although tolerances for BIK and NOXA are similar to BIM and PUMA in Jurkat and SKW6.4 cells, much higher tolerances for BIK and NOXA are observed in other lines (Figures $5 \mathrm{~b}$ and $\mathrm{c}$ ). It is possible that these differences reflect

a
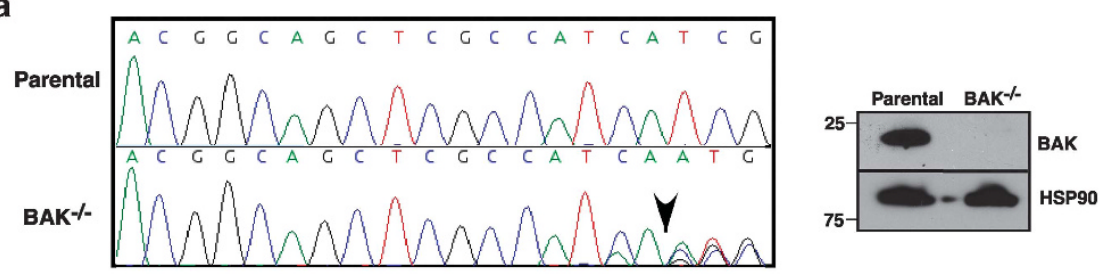

b

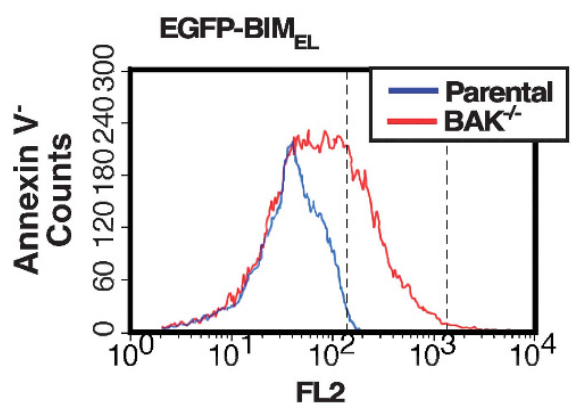

C Jurkat $\mathrm{BAK}^{-1-}$

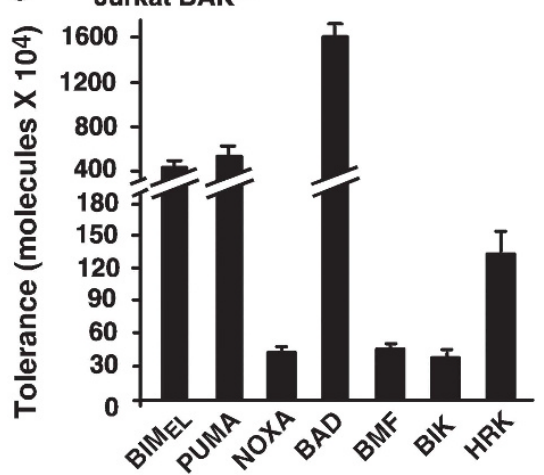

Figure 6 Effect of BAK gene interruption on BH3-only tolerance in Jurkat cells. (a) Partial sequence analysis (left) and immunoblot (right) comparing BAK in parental and cloned $B A K^{--}$cells. (b) Parental and cloned Jurkat $B A K^{--}$cells were transfected with EGFP-BIM, incubated for $24 \mathrm{~h}$, stained with Annexin-V and examined by flow microfluorimetry. Shown is the histogram for EGFP fluorescence in Annexin-V-negative cells. (c) Summary of BH3-only protein tolerances in Jurkat $B A K^{-1-}$ cells. Error bars in c: mean \pm S.D. of three independent experiments
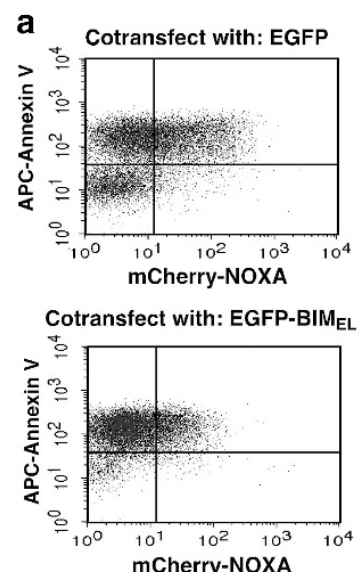

b

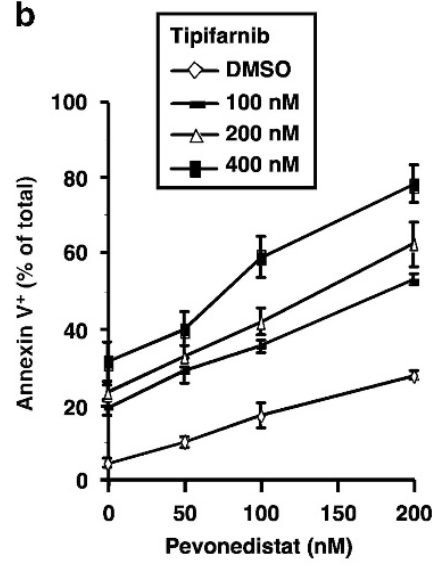

C

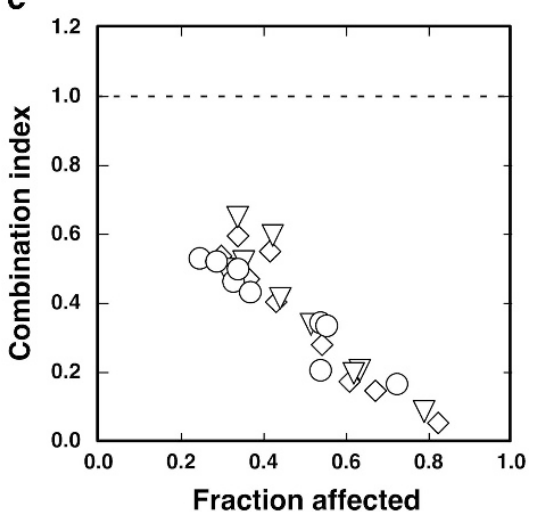

Figure 7 Use of BH3-only protein tolerance to identify a synergistic anticancer drug combination. (a) Twenty-four hours after Jurkat cells transfected with EGFP+mCherryNOXA (upper panel) or EGFP-BIM $\mathrm{EL}_{+}+\mathrm{mCherry}-\mathrm{NOXA}$ (bottom panel), cells were collected and stained with APC-Annexin-V. The samples were initially gated on EGFP ${ }^{+}$or EGFP$\mathrm{BIM}_{\mathrm{EL}}^{+}$cells, then analyzed for mCherry-NOXA and APC-Annexin-V fluorescence. A representative experiment (already gated on EGFP- or EGFP-BIM $\mathrm{EL}_{\mathrm{EL}}$-positive cells) from three independent experiments is shown. (b) After Jurkat cells were treated with indicated concentrations of pevonedistat and tipifarnib for $24 \mathrm{~h}$, apoptosis was assessed by Annexin-V binding. (c) Plot showing combination index ${ }^{60}$ versus fraction of cells killed for three independent experiments (depicted by three different symbols) in which Jurkat cells were treated with pevonedistat and tipifarnib as in panel b. Combination index $<1$ indicates synergy. Error bars in panel $\mathbf{b}$ : mean \pm S.D. of three independent experiments 
the presence of other binders for these proteins in certain cell types. ${ }^{53,54}$ Whatever the cause, the higher tolerance for NOXA accurately predicts $\mathrm{K} 562$ cell resistance to bortezomib. In contrast, bortezomib also upregulates BIM (Figure 5e), a less tolerated BH3-only protein in HCT116 cells (Figure $5 \mathrm{c}$ ), explaining why these cells are killed by bortezomib (Figure $5 d$ ) despite their high tolerance of NOXA.

Consistent with earlier qualitative studies, ${ }^{25-30}$ the present analysis suggests that apoptosis is governed by the balance between the number of $\mathrm{BH} 3$-only protein molecules present and the ability of cells to tolerate an increase in those proteins. For example, although the bortezomib-induced rise in Noxa is roughly 15-fold in both Jurkat and K562 cells (Figures 5e and f), Jurkat cells undergo apoptosis and K562 cells do not (Figure 5d). This appears to reflect the fact that the increase in Jurkat cells, albeit smaller in terms of the absolute number of molecules (Figure 5e), takes the Noxa level above the level that Jurkat cells can tolerate (Figure $3 \mathrm{k}$ ), whereas the increase in K562 cells does not exceed the ability of K562 cells to survive with Noxa present (Figure 5b).

The present approach also helps understand the action of certain combinations. In particular, the present analysis suggests that upregulation of one $\mathrm{BH} 3$-only protein leads to increased sensitivity to another (Figure 7a), likely reflecting the fact that pro- and antiapoptotic BCL2 family members form a network that serves to buffer changes in death signaling. ${ }^{2,45}$ As illustrated by the tipifarnib/pevonedistat combination (Figures $7 \mathrm{~b}$ and $\mathrm{c}$ ), the ability of individual drugs to upregulate complementary $\mathrm{BH} 3$ proteins can be utilized to identify drug combinations that induce synergistic killing in vitro.

Finally, this study also provides insight into the relative importance of anti- and proapoptotic proteins in setting the apoptotic threshold. In particular, we observed that overexpression of antiapoptotic BCL2 family members impacts the buffering capacity of sensitive cells much more than downregulation of endogenous BIM (Figure $4 \mathrm{e}$ versus $4 \mathrm{j}$ ). These observations have several implications. First, they confirm that $\mathrm{BH} 3-$ only tolerances are not a fixed property of cells, but instead vary depending on the expression of other pro- and antiapoptotic proteins (Figure 4), which in turn reflect conditions in which those cells find themselves. ${ }^{4,6}$ Second, the observation that antiapoptotic BCL2 family members preferentially impact $\mathrm{BH} 3$-only tolerance provides an explanation for the ability of a short-lived BCL2 family member like MCL1 to modulate apoptosis so effectively. ${ }^{4,55}$ Third, the observation that individual antiapoptotic BCL2 paralogs affect tolerances of various $\mathrm{BH} 3$-only proteins somewhat differently (Figure $4 \mathrm{e}$ ) provides additional support for the notion that antiapoptotic BCL2 family members have somewhat specialized functions (e.g., Noxa binding preferentially to MCL1 over BCL2) 29,37 rather than being equivalent. Finally, our observation that apoptotic tolerances are affected more by overexpression of antiapoptotic BCL2 family members than by downregulation of BH3-only family members also provides a potential biochemical explanation for the observation that amplification of the $B C L X$ and MCL 1 genes is much more common than mutation or deletion of genes encoding $\mathrm{BH} 3-$ only proteins during cancer development. ${ }^{8}$

\section{Materials and Methods}

Materials. Reagents were obtained from the following suppliers: Q-VD-OPh from SM Biochemicals (Anaheim, CA, USA), bortezomib and TAK-228 (previously known as MLN0128) from Chemietek (Indianapolis, IN, USA), pevonedistat from Active Biochem (Maplewood, NJ, USA), tipifarnib from the Drug Synthesis Branch of the National Cancer Institute (Bethesda, MD, USA), glutathione from Sigma-Aldrich (St. Louis, MO, USA), glutathione-agarose and FITC from Thermo Scientific (Waltham, MA, USA), S protein-agarose and $\mathrm{Ni}^{2+}$-NTA-agarose from Novagen (Madison, WI, USA), FITC Quantitation Beads (catalog number 555A) from Bangs Laboratories (Fishers, IN, USA) and purified HRK protein from R\&D Systems (Minneapolis, MN).

Antibodies. Antibodies to the following antigens were purchased from the indicated suppliers: GFP (catalog number 2555 S), BIM (rabbit polyclonal 2819 S), BAD (rabbit polyclonal $9292 \mathrm{~S}$ ), BIK (rabbit polyclonal $4592 \mathrm{~S}$ ), BAX (rabbit polyclonal $2774 \mathrm{~S}$ ), BCLX (rabbit monoclonal clone 54H) and MCL1 (rabbit polyclonal 4572 S) from Cell Signaling Technology (Danvers, MA, USA); BCL2 (mouse monoclonal clone 124) from DAKO (Carpenteria, CA, USA); cytochrome $c$ (murine monoclonal 7H8.2C12) from BD Biosciences (San Diego, CA, USA); NOXA (mouse monoclonal clone 114C307.1) and BMF (rat monoclonal antibody 9G10) from Enzo Life Sciences (Farmington, NY, USA); HRK from Thermo Scientific; BAK (06-536 rabbit polyclonal) from Millipore (Billerica, MA, USA); and actin (goat polyclonal) and PUMA (mouse monoclonal SC-374223) from Santa Cruz Biotechnology (Santa Cruz, CA, USA). Notably, all polyclonal antibodies to BCL2 family members except BIK were raised against epitopes that excluded the $\mathrm{N}$-terminus per se. Anti-S peptide antibody was raised as described. ${ }^{56}$

Protein expression and purification. Plasmid encoding Bak $\Delta T M$ (GenBank BC004431, residues 1-186) in pET29b $(+)^{57}$ was a kind gift from Qian Liu and Kalle Gehring (McGill University, Montreal, Canada). Procedures to purify $\mathrm{His}_{6}$-tagged PUMA, BAD, tBID, NOXA and BAK $\Delta \mathrm{TM}^{20,21,37}$ as well as BCL2 $\Delta \mathrm{TM}$, $B C L X_{L} \Delta T M$ and MCL1 $\Delta T^{24,49}$ have been previously described. The EGFP open reading frame was cloned into pGEX-4 T-1 to yield a construct with EGFP fused at its N-terminus to GST. The open reading frames for BIK (GenBank BC001599) and BMF (GenBank BC069328) were cloned into $\mathrm{pET} 29 \mathrm{a}(+)$ with an S peptide tag at the $\mathrm{N}$-terminus and $\mathrm{His}_{6}$ tag on the $\mathrm{C}$-terminus. All plasmids were sequenced to verify the described alteration and confirm that no additional mutations were present.

Plasmids were transformed into $E$. coli BL21 by heat shock. After cells were grown to an optical density of 0.8 , IPTG was added to $1 \mathrm{mM}$ and incubation was continued for $3 \mathrm{~h}$ at $37^{\circ} \mathrm{C}$ (GST-EGFP, S-BIK-His 6 , S-BMF-His 6 ). Bacteria were then washed and sonicated intermittently on ice in TS buffer ( $150 \mathrm{mM} \mathrm{NaCl}$ containing $10 \mathrm{mM}$ Tris$\mathrm{HCl}(\mathrm{pH} 7.4)$ and $1 \mathrm{mM} \mathrm{PMSF})$. All further steps were performed at $4{ }^{\circ} \mathrm{C}$.

After GST-EGFP was incubated with glutathione-agarose for $4 \mathrm{~h}$ at $4{ }^{\circ} \mathrm{C}$, beads were washed twice with 20-25 volumes of TS buffer and eluted with TS containing $20 \mathrm{mM}$ reduced glutathione for $30 \mathrm{~min}$ at $4{ }^{\circ} \mathrm{C}$.

After S-BIK-His ${ }_{6}$ and S-BMF-His 6 were applied to $\mathrm{S}$ protein-agarose overnight at $4{ }^{\circ} \mathrm{C}$, columns were washed with 20 volumes of TS buffer and eluted with $3 \mathrm{M} \mathrm{MgCl}_{2}$ for $30 \mathrm{~min}$ at $4^{\circ} \mathrm{C}$.

Cell culture. Cell lines were obtained from the following sources: Jurkat (T-cell ALL) from Paul Leibson (Mayo Clinic, Rochester, MN, USA); SKW6.4 (B cell ALL) from American Type Culture Collection (Manassas, VA, USA); K562 (CML blast crisis) and HCT116 (colon cancer) from Richard Jones and Bert Vogelstein, respectively (both at Johns Hopkins University). All cell lines were authenticated by short tandem repeat profiling in the Mayo Clinic Advanced Genomics Technology Center. Leukemia cell lines were maintained at densities below $10^{6} \mathrm{cell} / \mathrm{s} / \mathrm{ml}$ in RPMI-1640 medium containing 10\% heat-inactivated fetal bovine serum, 100 units/ $\mathrm{ml}$ penicillin $\mathrm{G}, 100 \mu \mathrm{g} / \mathrm{ml}$ streptomycin and $2 \mathrm{mM}$ glutamine.

BAK gene interruption. Oligonucleotides (5'-ACGGCAGCTCGCCATCATCG $-3^{\prime}$ ) guiding to nucleotides $162-184$ of the human BAK open reading frame (GenBank accession number AF520590.1) were synthesized, annealed, and cloned into the BsmBI site of the lentiCRISPRv2 (Addgene, Cambridge, MA, USA) plasmid. Viruses were packaged in HEK293T cells by transfecting with the packaging vector psPAX2, envelope vector pMD2.G, and lentiCRISPRv2-Bak(162-184) using Lipofectamine 2000. Culture supernatants were filtered and incubated with log phase Jurkat cells for $48 \mathrm{~h}$. Two days after viral transduction, Jurkat cells were selected with $3 \mu \mathrm{g} / \mathrm{ml}$ puromycin and cloned by limiting dilution. BAK knockout was verified by genomic DNA sequencing and immunoblotting. 
Apoptosis assays. Staining with APC-coupled Annexin-V was performed and analyzed as previously described. ${ }^{45}$ Alternatively, after drug treatment, cells were stained with propidium iodide in $0.1 \%(\mathrm{w} / \mathrm{v})$ sodium citrate containing $0.1 \%(\mathrm{w} / \mathrm{v})$ Triton X-100 to quantitative subdiploid events as described. ${ }^{45}$ Samples were subjected to flow microfluorimetry using a Becton Dickinson FACSCanto II flow cytometer (Becton Dickinson, Mountain View, CA, USA) and analyzed using Becton Dickinson CellQuest software.

Western blotting. Cells exposed to increasing concentrations of indicated drugs for 24 or $48 \mathrm{~h}$ were pelleted for protein isolation. To calculate the protein expression per cell, whole-cell lysates were prepared as described previously. ${ }^{58}$ Protein from $3 \times 10^{5}$ cells and measured amounts of purified BCL2 family proteins were loaded as indicated in the figure legends. Alternatively, serial dilutions of cells treated with the highest drug concentration were included on each blot (e.g., Figure 5). Sample preparation, SDS-PAGE, transfer to nitrocellulose membrane, immunoblotting and detection by enhanced chemiluminescence were performed as described. ${ }^{58}$ Films exposed in the linear range were scanned on a Hewlett Packard Scanjet $4 \mathrm{C}$ scanner (Hewlett Packard, Palo Alto, CA, USA) and quantified using Image J software (https:// rcsb.info.nih.gov). Protein levels were calculated based on standard curves contained on each blot and generated from each independent experiment.

Mammalian expression plasmids and transfection. Plasmid encoding S peptide-tagged wild-type BCL2 and S peptide-tagged MCL1 were described before. $^{45,49}$ cDNAs encoding human BIM $\mathrm{EL}_{\text {L }}$ (GenBank AF032457), PUMA (GenBank NM_001127242), NOXA (GenBank NM_021127), BAD (GenBank AF021792), BIK (GenBank BC001599), BMF (GenBank BC069328) and HRK (GenBank U76376) were cloned into the Xhol and BamHI sites of pEGFP-C1 (Clontech, Mountain View, CA, USA) to yield EGFP-tagged constructs.

To assess the tolerance for $\mathrm{BH}$-only proteins, log phase cells growing in antibioticfree medium were transiently transfected with the indicated plasmid using a BTX 830 square wave electroporator delivering a single pulse at $240 \mathrm{mV}$ for $10 \mathrm{msec}$. Cells were incubated for $24 \mathrm{~h}$ and analyzed for APC-annexin-V binding.

For MCL1 or BCL2 overexpression assays, log phase Jurkat cells suspended in $400 \mu \mathrm{l}$ cytomix ${ }^{59}$ containing $40 \mu \mathrm{g}$ pSPN (or PSPN encoding BCL2 or MCL1) and $5 \mu \mathrm{g}$ plasmid encoding mCherry were transfected by electroporation on day 1 as described in the preceding paragraph. On day 2, cells were transfected with $10 \mu \mathrm{g}$ EGFP-tagged BH3 protein constructs. On day 3, cells were collected, stained with APC-annexin-V and analyzed on a Becton Dickinson LSRII flow cytometer (Becton Dickinson) using the following lasers and filters: mCherry, $532 \mathrm{~nm}$ laser, 610/20 filter; EGFP, $488 \mathrm{~nm}$ laser, 530/30 filter; APC, $633 \mathrm{~nm}$ laser, 660/20 filter. After collection of 100000 events, binding of APC-annexin- $\mathrm{V}$ was assessed on cells that were positive for both mCherry and EGFP. Alternatively, for the tolerance assay, $\mathrm{mCherry}^{+} \mathrm{APC}^{-}$cells were gated.

Calculation of BH3-only tolerance. After transient transfection and staining with APC-coupled annexin-V as described above, 100000 events were collected on a Becton Dickinson FACSCalibur flow cytometer and analyzed by gating on $\mathrm{APC}^{-}$cells. To estimate the $\mathrm{BH} 3-$ only protein tolerance, we arbitrarily set a cutoff such that only $2 \%$ of selected cells expressed higher EGFP levels. During each experiment, calibration beads containing known amounts of FITC were also assayed; and the cutoffs were converted into the FITC equivalents. As illustrated in Supplementary Figure 4, the relationship between FITC equivalents and EGFP expression (a linear factor of 4.69) was established by measuring FITC and EGFP fluorescence between 515 and $545 \mathrm{~nm}$ using the same excitation laser on a fluorimetric plate reader.

\section{Conflict of Interest}

The authors declare no conflict of interest.

Acknowledgements. This work was supported in part by R01 CA166741. HD was also supported by the Hundred-Talent Program of Chinese Academy of Sciences. We gratefully acknowledge assistance of the Mayo Clinic Microscopy and Cell Analysis Core for cell sorting, helpful discussions with members of the Kaufmann laboratory, editorial assistance of Deb Strauss and thoughtful comments of the anonymous referees.

1. Fuchs $\mathrm{Y}$, Steller H. Programmed cell death in animal development and disease. Cell 2011; 147: $742-758$
2. Chen HC, Kanai M, Inoue-Yamauchi A, Tu HC, Huang Y, Ren D et al. An interconnected hierarchical model of cell death regulation by the BCL-2 family. Nat Cell Biol 2015; 17 : $1270-1281$.

3. Johnstone RW, Ruefli AA, Lowe SW. Apoptosis. A link between cancer genetics and chemotherapy. Cell 2002; 108: 153-164.

4. Cory S, Adams JM. The Bcl2 family: regulators of the cellular life-or-death switch. Nat Rev Cancer 2002; 2: 647-656.

5. Sarosiek KA, Ni Chonghaile T, Letai A. Mitochondria: gatekeepers of response to chemotherapy. Trends Cell Biol 2013; 23: 612-619.

6. Delbridge AR, Grabow S, Strasser A, Vaux DL. Thirty years of BCL-2: translating cell death discoveries into novel cancer therapies. Nat Rev Cancer 2016; 16: 99-109.

7. Vaux DL, Cory S, Adams JM. Bcl-2 gene promotes haemopoietic cell survival and cooperates with c-myc to immortalize pre-B cells. Nature 1988; 335: 440-442.

8. Beroukhim R, Mermel $\mathrm{CH}$, Porter D, Wei G, Raychaudhuri S, Donovan J et al. The landscape of somatic copy-number alteration across human cancers. Nature 2010; 463: 899-905.

9. Zhang L, Yu J, Park BH, Kinzler KW, Vogelstein B. Role of BAX in the apoptotic response to anticancer agents. Science 2000; 290: 989-992.

10. Ng KP, Hillmer AM, Chuah CT, Juan WC, Ko TK, Teo AS et al. A common BIM deletion polymorphism mediates intrinsic resistance and inferior responses to tyrosine kinase inhibitors in cancer. Nat Med 2012; 18: 521-528.

11. Katz SG, Labelle JL, Meng H, Valeriano RP, Fisher JK, Sun $\mathrm{H}$ et al. Mantle cell lymphoma in cyclin D1 transgenic mice with Bim-deficient B cells. Blood 2014; 123: 884-893.

12. Delbridge AR, Grabow $S$, Bouillet $P$, Adams JM, Strasser A. Functional antagonism between pro-apoptotic BIM and anti-apoptotic BCL-XL in MYC-induced lymphomagenesis. Oncogene 2015; 34: 1872-1876.

13. Cory S, Huang DC, Adams JM. The Bcl-2 family: roles in cell survival and oncogenesis. Oncogene 2003; 22: 8590-8607.

14. Danial NN, Korsmeyer SJ. Cell death: critical control points. Cell 2004; 116: 205-219.

15. Oltvai ZN, Korsmeyer SJ. Checkpoints of dueling dimers foil death wishes. Cell 1994; 79 : 189-192.

16. Willis SN, Fletcher Jl, Kaufmann T, van Delft MF, Chen L, Czabotar PE et al. Apoptosis initiated when BH3 ligands engage multiple Bcl-2 homologs, not Bax or Bak. Science 2007; 315: 856-859.

17. Merino D, Giam M, Hughes PD, Siggs OM, Heger K, O'Reilly LA et al. The role of BH3-only protein Bim extends beyond inhibiting Bcl-2-like prosurvival proteins. J Cell Biol 2009; 186: 355-362.

18. Walensky LD, Pitter K, Morash J, Oh KJ, Barbuto S, Fisher J et al. A stapled BID BH3 helix directly binds and activates BAX. Mol Cell 2006; 24: 199-210.

19. Gavathiotis E, Reyna DE, Davis ML, Bird GH, Walensky LD. BH3-triggered structural reorganization drives the activation of proapoptotic BAX. Mol Cell 2010; 40: 481-492.

20. Dai H, Smith A, Meng XW, Schneider PA, Pang Y-P, Kaufmann SH. Transient binding of an activator $\mathrm{BH} 3$ domain to the Bak BH3-binding groove initiates Bak oligomerization. J Cell Biol 2011; 194: 39-48.

21. Dai H, Pang Y-P, Kaufmann SH. Evaluation of the BH3-only protein Puma as a direct Bak activator. J Biol Chem 2014; 289: 89-99.

22. Walensky LD. Direct BAKtivation. Nat Struct Mol Biol 2013; 20: 536-538.

23. Hockings C, Anwari K, Ninnis RL, Brouwer J, O'Hely M, Evangelista M et al. Bid chimeras indicate that most $\mathrm{BH} 3-$ only proteins can directly activate Bak and Bax, and show no preference for Bak versus Bax. Cell Death Dis 2015; 6: e1735.

24. Dai H, Ding H, Meng XW, Peterson KL, Schneider PA, Karp JE et al. Constitutive BAK activation as a determinant of drug sensitivity in malignant lymphohematopoietic cells. Genes Dev 2015; 29: 2140-2152.

25. O'Connor L, Strasser A, O'Reilly LA, Hausmann G, Adams JM, Cory S et al. Bim: a novel member of the Bcl-2 family that promotes apoptosis. EMBO J 1998; 17: 384-395.

26. Oda E, Ohki R, Murasawa H, Nemoto J, Shibue T, Yamashita T et al. Noxa, a BH3-only member of the Bcl-2 family and candidate mediator of p53-induced apoptosis. Science 2000; 288: 1053-1058.

27. Nakano K, Vousden KH. PUMA, a novel proapoptotic gene, is induced by p53. Mol Cell 2001; 7: 683-694.

28. Cheng EH, Wei MC, Weiler S, Flavell RA, Mak TW, Lindsten T et al. BCL-2, BCL-X(L) sequester $\mathrm{BH} 3$ domain-only molecules preventing BAX-and BAK-mediated mitochondrial apoptosis. Mol Cell 2001; 8: 705-711.

29. Chen L, Willis SN, Wei A, Smith BJ, Fletcher Jl, Hinds MG et al. Differential targeting of prosurvival $\mathrm{Bcl}-2$ proteins by their $\mathrm{BH} 3-$ only ligands allows complementary apoptotic function. Mol Cell 2005; 17: 393-403.

30. Llambi F, Moldoveanu T, Tait SW, Bouchier-Hayes L, Temirov J, McCormick LL et al. A unified model of mammalian BCL-2 protein family interactions at the mitochondria. Mol Cell 2011; 44: 517-531.

31. Vousden KH, Lu X. Live or let die: the cell's response to p53. Nat Rev Cancer 2002; 2: 594-604.

32. Villunger A, Michalak EM, Coultas L, Mullauer F, Bock G, Ausserlechner MJ et al. p53- and drug-induced apoptotic responses mediated by $\mathrm{BH} 3$-only proteins Puma and Noxa. Science 2003; 302: 1036-1038.

33. Cragg MS, Jansen ES, Cook M, Harris C, Strasser A, Scott CL. Treatment of B-RAF mutant human tumor cells with a MEK inhibitor requires Bim and is enhanced by a $\mathrm{BH} 3$ mimetic. J Clin Invest 2008; 118: 3582-3584. 
34. Ding H, Hackbarth J, Schneider PA, Peterson KL, Meng XW, Dai H et al. Cytotoxicity of farnesyltransferase inhibitors in lymphoid cells mediated by MAPK pathway inhibition and Bim upregulation. Blood 2011; 118: 4872-4881.

35. Yun S, Vincelette ND, Knorr KLB, Schneider PA, Peterson KL, Flatten KS et al. Dual mTOR inhibitiors induce Bim-dependent apoptosis in acute lymphoblastic leukmeia via inhibition of elF4E/elF4G and activation of NF-kB/Egr-1. Blood 2016; 127: 2711-2722.

36. Nikiforov MA, Riblett M, Tang WH, Gratchouck V, Zhuang D, Fernandez Y et al. Tumor cellselective regulation of NOXA by c-MYC in response to proteasome inhibition. Proc Natl Acad Sci USA 2007; 104: 19488-19493.

37. Smith AJ, Dai H, Correia C, Lee S-H, Takahashi R, Kaufmann SH. Noxa/Bcl-2 interactions contribute to bortezomib resistance in human lymphoid cells. J Biol Chem 2011; 286: 17682-17692.

38. Knorr KLB, Schneider PA, Meng XW, Dai H, Smith BD, Hess AD et al. MLN4924 induces Noxa upregulation in acute myelogenous leukemia and synergizes with Bcl-2 inhibitors. Cell Death Differ 2015; 22: 2133-2142.

39. Deng J, Carlson N, Takeyama K, Dal Cin P, Shipp M, Letai A. BH3 profiling identifies three distinct classes of apoptotic blocks to predict response to ABT-737 and conventional chemotherapeutic agents. Cancer Cell 2007; 12: 171-185.

40. Ryan JA, Brunelle JK, Letai A. Heightened mitochondrial priming is the basis for apoptotic hypersensitivity of CD4+ CD8+ thymocytes. Proc Natl Acad Sci USA 2010; 107: 12895-12900.

41. Ni Chonghaile T, Sarosiek KA, Vo TT, Ryan JA, Tammareddi A, Moore Vdel G et Pretreatment mitochondrial priming correlates with clinical response to cytotoxic chemotherapy. Science 2011; 334: 1129-1133

42. Vo TT, Ryan J, Carrasco R, Neuberg D, Rossi DJ, Stone RM et al. Relative mitochondria priming of myeloblasts and normal HSCs determines chemotherapeutic success in AML. Cell 2012; 151: 344-355.

43. Montero J, Sarosiek KA, DeAngelo JD, Maertens O, Ryan J, Ercan D et al. Drug-induced death signaling strategy rapidly predicts cancer response to chemotherapy. Cell 2015; 160 977-989.

44. Krajewski K, Tanaka S, Takayama S, Schibler MJ, Fenton W, Reed JC. Investigation of the subcellular distribution of the Bcl-2 oncoprotein: residence in the nuclear envelope endoplasmic reticulum, and outer mitochondrial membranes. Cancer Res 1993; 53: 4701-4714.

45. Meng XW, Lee SH, Dai H, Loegering D, Yu C, Flatten $\mathrm{K}$ et al. Mcl-1 as a buffer for proapoptotic Bcl-2 family members during TRAlL-induced apoptosis: a mechanistic basis for sorafenib (Bay 43-9006)-induced TRAlL sensitization. J Biol Chem 2007; 282 29831-29846.
46. Rooswinkel RW, van de Kooij $B$, de Vries E, Paauwe M, Braster R, Verheij $M$ et al. Antiapoptotic potency of $\mathrm{Bcl}-2$ proteins primarily relies on their stability, not binding selectivity. Blood 2014; 123: 2806-2815.

47. Koopman G, Reutelingsperger CPM, Kuijten GAM, Keehnen RMJ, Pals ST, van Oers MHJ. Annexin $\mathrm{V}$ for flow cytometric detection of phosphatidylserine expression on $\mathrm{B}$ cells undergoing apoptosis. Blood 1994; 84: 1415-1420.

48. Martin SJ, Reutelingsperger CP, McGahon AJ, Rader JA, van Schie RC, LaFace DM et al. Early redistribution of plasma membrane phosphatidylserine is a general feature of apoptosis regardless of the initiating stimulus: inhibition by overexpression of Bcl-2 and Abl. J Exp Med 1995; 182: 1545-1556.

49. Dai H, Meng XW, Lee S-H, Schneider PA, Kaufmann SH. Context-dependent Bcl-2/Bak interactions regulate lymphoid cell apoptosis. J Biol Chem 2009; 284: 18311-18322.

50. Friedman AA, Letai A, Fisher DE, Flaherty KT. Precision medicine for cancer with nextgeneration functional diagnostics. Nat Rev Cancer 2015; 15: 747-756.

51. Werneburg NW, Guicciardi ME, Bronk SF, Kaufmann SH, Gores GJ. Tumor necrosis factorrelated apoptosis-inducing ligand activates a lysosomal pathway of apoptosis that is regulated by Bcl-2 proteins. J Biol Chem 2007; 282: 28960-28970.

52. Du H, Wolf J, Schafer B, Moldoveanu T, Chipuk JE, Kuwana T. BH3 domains other than Bim and Bid can directly activate Bax/Bak. J Biol Chem 2011; 286: 491-501.

53. Lowman XH, McDonnell MA, Kosloske A, Odumade OA, Jenness C, Karim CB et al. The proapoptotic function of Noxa in human leukemia cells is regulated by the kinase Cdk5 and by glucose. Mol Cell 2010; 40: 823-833.

54. Roufayel R, Johnston DS, Mosser DD. The elimination of miR-23a in heat-stressed cells promotes NOXA-induced cell death and is prevented by HSP70. Cell Death Dis 2014; 5: e1546.

55. Gores GJ, Kaufmann SH. Selectively targeting Mcl-1 for the treatment of acute myelogenous leukemia and solid tumors. Genes Dev 2012; 26: 305-311.

56. Hackbarth JS, Lee S-H, Meng XW, Vroman BT, Kaufmann SH, Karnitz LM. S-peptide epitope tagging for protein purification, expression monitoring and localization in mammalian cells. BioTechniques 2004; 37: 835-839.

57. Moldoveanu T, Liu Q, Tocilj A, Watson M, Shore G, Gehring K. The X-ray structure of a BAK homodimer reveals an inhibitory zinc binding site. Mol Cell 2006; 24: 677-688.

58. Kaufmann SH. Reutilization of immunoblots after chemiluminescent detection. Anal Biochem 2001; 296: 283-286.

59. van den Hoff MJB, Moorman AFM, Lamers WH. Electroporation in "intracellular" buffer increases cell survival. Nucleic Acids Res 1992; 20: 2902.

60. Chou T-C, Talalay P. Quantitative analysis of dose-effect relationships: the combined effects of multiple drugs or enzyme inhibitors. Adv Enzyme Regulation 1984; 22: 27-55.

\section{Supplementary Information accompanies this paper on Cell Death and Differentiation website (http://www.nature.com/cdd)}

